
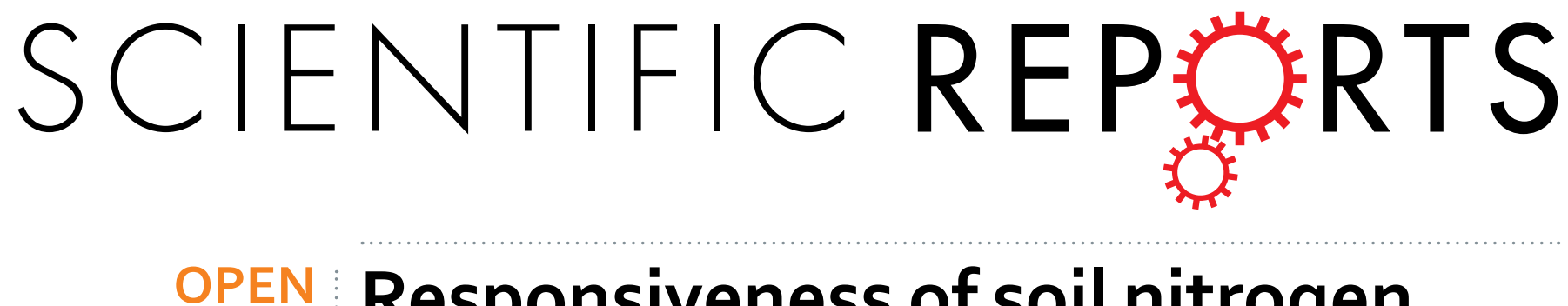

\title{
Responsiveness of soil nitrogen fractions and bacterial communities to afforestation in the Loess Hilly \\ Region (LHR) of China
}

Received: 01 March 2016

Accepted: 02 June 2016

Published: 23 June 2016

\author{
Chengjie Ren ${ }^{1,2}$, Pingsheng Sun ${ }^{1,2}$, Di Kang ${ }^{2,3}$, Fazhu Zhao ${ }^{4}$, Yongzhong Feng ${ }^{1,2}$, \\ Guangxin Ren ${ }^{1,2}$, Xinhui Han ${ }^{1,2}$ \& Gaihe Yang ${ }^{1,2}$
}

In the present paper, we investigated the effects of afforestation on nitrogen fractions and microbial communities. A total of 24 soil samples were collected from farmland (FL) and three afforested lands, namely Robinia pseudoacacia L (RP), Caragana korshinskii Kom (CK), and abandoned land (AL), which have been arable for the past 40 years. Quantitative PCR and Illumina sequencing of $16 \mathrm{~S}$ rRNA genes were used to analyze soil bacterial abundance, diversity, and composition. Additionally, soil nitrogen $(\mathrm{N})$ stocks and fractions were estimated. The results showed that soil $\mathrm{N}$ stock, $\mathrm{N}$ fractions, and bacterial abundance and diversity increased following afforestation. Proteobacteria, Acidobacteria, and Actinobacteria were the dominant phyla of soil bacterial compositions. Overall, soil bacterial compositions generally changed from Actinobacteria (Acidobacteria)-dominant to Proteobacteriadominant following afforestation. Soil $\mathrm{N}$ fractions, especially for dissolved organic nitrogen (DON), were significantly correlated with most bacterial groups and bacterial diversity, while potential competitive interactions between Proteobacteria (order Rhizobiales) and Cyanobacteria were suggested. In contrast, nitrate nitrogen $\left(\mathrm{NO}_{3}{ }^{-}-\mathrm{N}\right)$ influenced soil bacterial compositions less than other $\mathrm{N}$ fractions. Therefore, the present study demonstrated that bacterial diversity and specific species respond to farmland-to-forest conversion and hence have the potential to affect $\mathrm{N}$ dynamic processes in the Loess Plateau.

With rising concern regarding climatic consequences, afforestation has often been proposed as an effective and cost-efficient mitigation response to climate change ${ }^{1,2}$. This widespread shift in ecosystem have strong potential to alter key ecosystem processes, the resultant alterations can affect $\mathrm{N}$ cycles at the ecosystem and regional scale ${ }^{3-5}$, further influence the forest $\mathrm{N}$ stock under the process of ecological restoration ${ }^{6}$. In fact, it has been estimated that soil nitrogen $(\mathrm{N})$ accounts for approximately $88 \%$ of the global plant $\mathrm{N}$ demand ${ }^{7}$, and changes in soil $\mathrm{N}$ availability greatly affect plant growth and productivity, particularly for rooting and canopy closure ${ }^{8}$. Meanwhile, afforestation has been demonstrated to enhance soil $\mathrm{N}$ accumulation ${ }^{9,10}$ and alter the soil $\mathrm{N}$ availability for soil bacteria growth $^{11,12}$, thereby potentially influencing the element cycles of terrestrial ecosystems $s^{5,6}$. Therefore, elucidating the response of soil $\mathrm{N}$ stocks and fractions to changes in the ecosystem, especially for below-ground ecosystems such as soil bacterial community, are essential to revealing the biogeochemical cycling process.

Soil $\mathrm{N}$ respond to the quantity and quality of soil organic matter (SOM) input with changes in the microbial process ${ }^{13,14}$. Changes in microbial communities are hypothesized to alter ecosystem functions, including $\mathrm{N}$ sequestration, $\mathrm{N}$ cycling, plant litter decomposition and soil $\mathrm{N}$ availability ${ }^{3,6,15}$. A variety of mechanism between the soil $\mathrm{N}$ and soil bacterial communities have been identified, including direct effects and indirect effects ${ }^{16}$. For example, soil bacteria decompose the SOM inputs, thereby changing the amount of dissolved organic nitrogen $^{12}$. As such, soil nitrogen-fixing bacteria fix atmospheric $\mathrm{N}$ and accelerate the soil nitrogen transformation ${ }^{16,17}$. However, soil $\mathrm{N}$ could offer a greater amount of resources, such as $\mathrm{NH}_{4}{ }^{+}$and $\mathrm{NO}_{3}{ }^{-}$, for soil bacteria to live

${ }^{1}$ College of Agronomy, Northwest A\&F University, Yangling, 712100 Shaanxi, China. ${ }^{2}$ The Research Center of Recycle Agricultural Engineering and Technology of Shaanxi Province, Yangling 712100 Shaanxi, China. ${ }^{3}$ College of Forestry, Northwest A\&F University, Yangling, 712100 Shaanxi, China. ${ }^{4}$ College of Urban and Environmental Science, Northwest University, Xi'an, 712100 Shaanxi, China. Correspondence and requests for materials should be addressed toX.H. (email: hanxinhui@nwsuaf.edu.cn) or G.Y. (email:ygh@nwsuaf.edu.cn) 
on ${ }^{18}$ and also alter the below-ground carbon (C) allocation, hence influencing the amount of C available to the microbe. It is also shown that DON is the most active component of soil organic matter and responds more rapidly than soil organic fractions to afforestation, which lead to significant modifications in soil nutrient stoichiometry, thereby affecting the microbial activity and nutrient availability ${ }^{13,17}$. Importantly, the shift in soil bacterial communities and the soil $\mathrm{N}$ fractions following afforestation and the interactions among these components may in turn provide feedback to $\mathrm{N}$ stock and plant productivity.

The Loess Hilly Region (LHR) of China, with severe soil erosion and low vegetation coverage ${ }^{19}$, plays a vital role in environmental changes including plant composition, biodiversity ${ }^{20}$, soil water condition ${ }^{21}$, soil nutrient conditions $^{8,22}$. To counteract soil erosion and nutrient loss, the Chinese government has implemented environmental protection policies since $1950^{23}$, including the "Grain to Green Project" (GTGP), which is a large-scale ecological rehabilitation project that has been ongoing since 1999 and has achieved initial success with more than 9.27 million ha of farmland afforested in $\mathrm{LHR}^{24}$. Several studies were mainly focused on in the physical and chemical properties of soil ${ }^{25,26}$ as well as biological features such as soil enzyme activity and soil microbial biomass after afforestation ${ }^{26,27}$. Thus far, little research has applied high throughput sequencing technology to assess the soil microbial diversity following afforestation, and the possibility that soil $\mathrm{N}$ fractions to afforestation as well as their relationship to soil bacterial communities remain unclear.

Here, we explored the effect of afforestation on the soil bacterial communities and the $\mathrm{N}$ fractions in the Loess Hilly Region (LHR) of China. We hypothesized that afforestation would result in changes in the soil bacteria, including bacterial abundance and diversity, these observed increase would be driven by above-ground inputs and below-ground soil parameters ${ }^{28}$. Coupled with increased soil $\mathrm{N}$ fractions following afforestation, we expected that changes in the specific bacterial species such as Rhizobiales, the branches of Alphaproteobacteria, would result in increased soil $\mathrm{N}$ stocks and fractions, especially for $\mathrm{DON}^{16}$. Therefore, the objectives of this study were as follows: 1) to study the effect afforestation on soil bacterial abundance, diversity and compositions; 2) to study the effect of afforestation on $\mathrm{N}$ stock and fractions; and 3) to explore the response of soil bacteria to the soil $\mathrm{N}$ fractions using the "best" model selection procedure.

\section{Results}

Changes in the TN stocks and fractions. The total nitrogen (TN) content and stocks at a depth of $0-10 \mathrm{~cm}$ in RP40, CK40 and AL40 were higher by $65.08-188.61 \%$ and $68.67-201.65 \%$, than those in FL (Fig. 1a,b), respectively. Compared with FL, the ammonium nitrogen (AN), dissolved organic nitrogen (DON) and microbial biomass nitrogen (MBN) contents in RP40 were more than 83.22-204.21\% higher, and similar trends were also found in CK40 and AL40 (115.87-156.33\% and 57.49-124.26\%, respectively) (Fig. 1c,e,f); however, the NN content was higher in AL40. The DON contents responded more sensitively than the other nitrogen fractions to afforestation (Similarity Percentages: SIMPER; average cumulative explanation of the difference in DON was $34.19 \%$, respectively).

Changes in soil bacterial abundance, diversity and composition. The soil bacterial 16S rRNA gene copy abundance differed significantly $(\mathrm{p}<0.05)$ and displayed an increasing trend from FL to RP40 after afforestation (Fig. 1g). The abundance of soil bacteria in RP40 was not significantly different from that in CK40, but greatly differed from that in AL40 and FL. Compared with the farmland, the alpha diversity (Shannon, H) in RP40, CK40 and AL40 significantly increased by $1.4 \%, 1.525 \%$ and $0.625 \%$, respectively $(\mathrm{P}<0.05)$ (Fig. $1 \mathrm{~h})$. The beta diversity of the soil bacterial communities was highly variable with respect to afforestation (Adonis: $\mathrm{R}_{2}=0.286, \mathrm{P}=0.001$ ), the soil bacterial communities between replicates in RP40 were more similar to that in CK40 than AL40 and FL, and both aggregation degrees of the sample points in AL40 were far away from that in FL (unweighted -Unifracted PCoA) (Fig. 2).

Changes in the relative abundance of specific taxa of soil bacteria at the phylum and class level were also observed (Figs 3 and 4 and Supplementary Tables S2 and S3). At the phylum level (average values $>=1 \%$ ), Proteobacteria, Actinobacteria and Acidobacteria were the most abundant and changed intensely in response to afforestation (Fig. 3), with average contributions of $28.7 \%, 25.4 \%$ and $15.80 \%$, respectively. The abundance of Actinobacteria in the farmland was higher than that in the forest, and the Proteobacteria and Acidobacteria in RP40, CK40 and AL40 were more abundant than in the farmland. However, the average abundance of Acidobacteria were higher in AL40 than in RP40 and CK40. Other phylum species, including Chloroflexi $\left(\mathrm{F}_{3,23}=5.889, \mathrm{P}=0.005\right)$, Cyanobacteria $\left(\mathrm{F}_{3,23}=18.636, \mathrm{P}<0.001\right)$ and Nitrospirae $\left(\mathrm{F}_{3,23}=3.624, \mathrm{P}=0.031\right)$ were also affected by afforestation. Furthermore, at the class level, compared with farmland, increases in the abundance of most class groups (average values $>=1 \%$ ) in response to conversion were observed except for Acidimicrobia and Phycisphaerae (Fig. 4). Practically speaking, within Proteobacteria, the Alphaproteobacteria were the most dominant class (Fig. 4), and the Gammaproteobacteria, coupled with Alphaproteobacteria, were extremely significantly influenced by the conversion of farmland to forest $(\mathrm{P}<0.001)$. Furthermore, Acidimicrobia and Nitrospirae were significantly changed $(\mathrm{p}<0.05)$.

Relationship between soil $\mathbf{N}$ fractions and soil bacteria. Significant correlations existed among the soil $\mathrm{N}$ fractions, bacterial abundance and alpha diversity (Shannon index, $\mathrm{H})(\mathrm{P}<0.01)$, except for the correlation between alpha diversity and NN content $(\mathrm{p}=0.053)$. Moreover, the changes in beta diversity were mainly due to changes in the relative abundances of specific bacteria taxa after afforestation, which were related to the soil $\mathrm{N}$ fractions (Figs 5 and 6 and Table 1). After analysis with the "best" model method, the current results showed that DON was the single best predictive factor of changes of specific species at the phylum and class level among the soil $\mathrm{N}$ fractions after afforestation (Table 1). Rredundancy analysis (RDA) showed that the changes in DON, MBN and AN were positively correlated with the abundance of Proteobacteria and were negatively correlated with the 

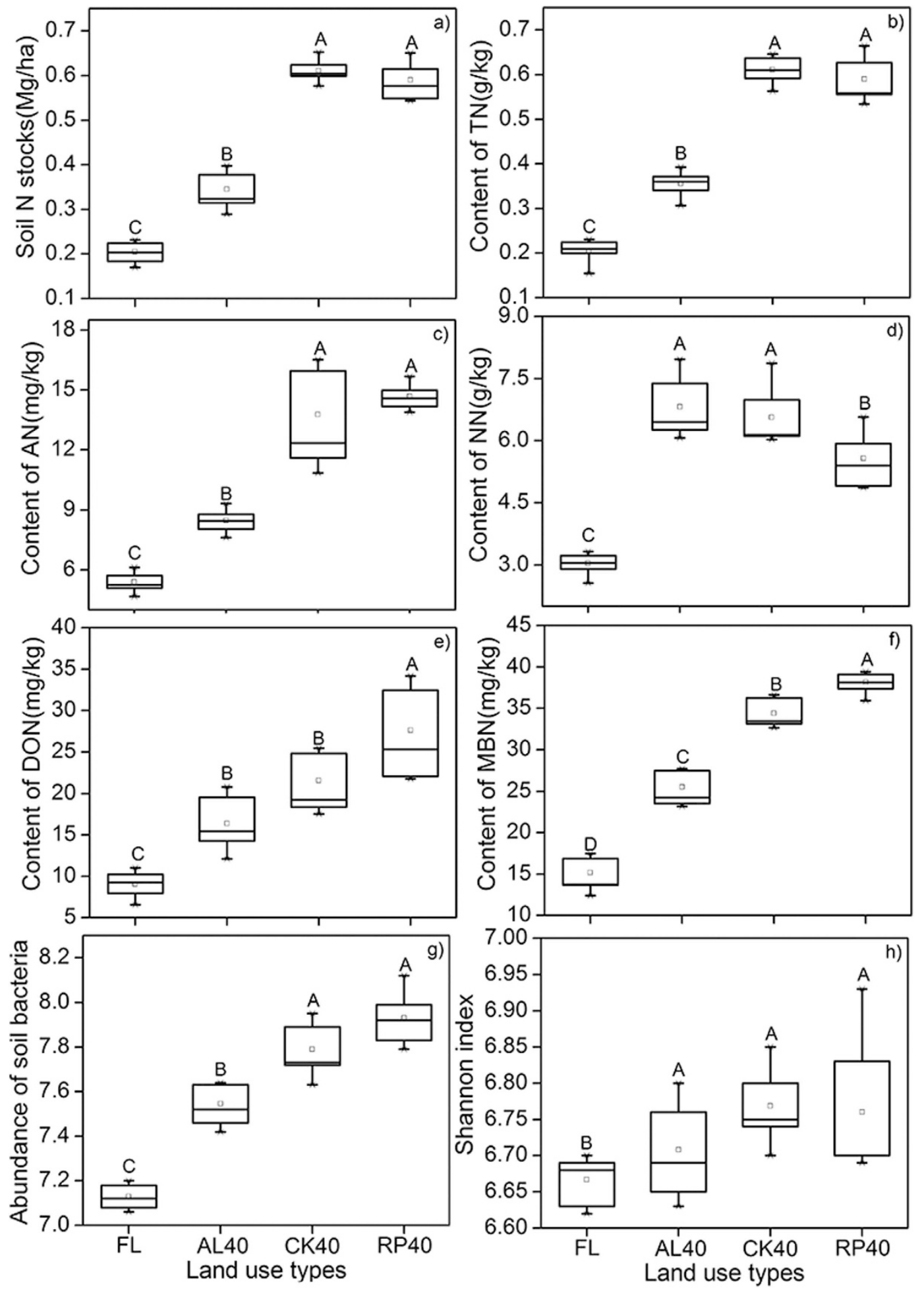

Figure 1. Changes of soil nitrogen $(\mathrm{N})$ stocks, soil nitrogen $(\mathrm{N})$ fractions. Different capital letters indicate significant differences among different land use types $(\mathrm{P}<0.05)$. The error bars show standard errors.

abundance of both Cyanobacteria and Chloroflexi (Fig. 5), whereas $\mathrm{N}$ fractions, except for NN, were also sensitive to the changes in the relative abundance of Alphaproteobacteria at the class level (Fig. 6).

\section{Discussion}

The change in land use from agriculture to forestry imply that the annual cycle of cultivating and harvesting crops was replaced by a considerably longer forest cycle ${ }^{23}$. As a result, the biogeochemically-relevant soil physicochemical properties can change due to the process of afforestation, which in turn can influence $\mathrm{N}$ dynamic ${ }^{6,9,29}$. 


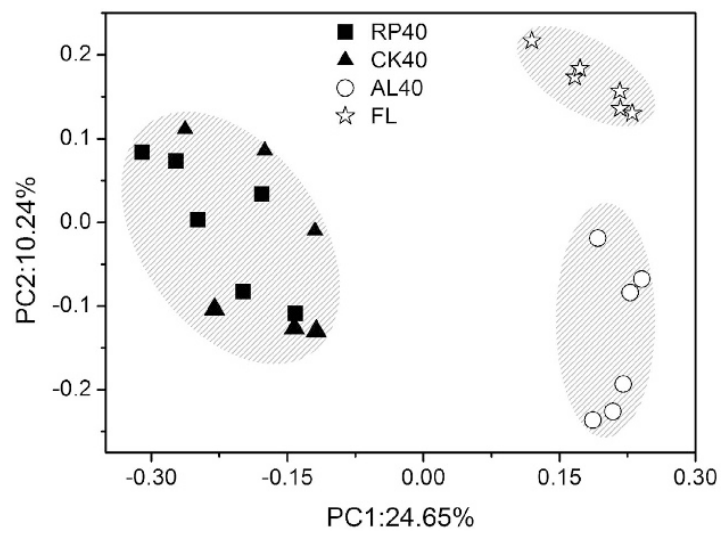

Figure 2. Unweighted-Unifracted PcoA of soil bacterial communities following afforestation.

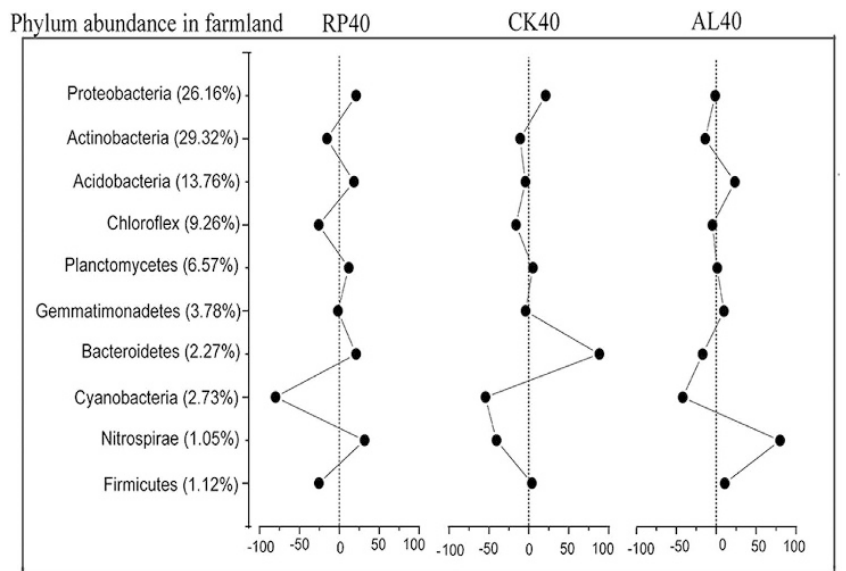

Percent change of the relative abundance in soil (\%)

Figure 3. Distribution of $16 \mathrm{~S}$ rRNA sequences across bacterial phyla communities following afforestation.

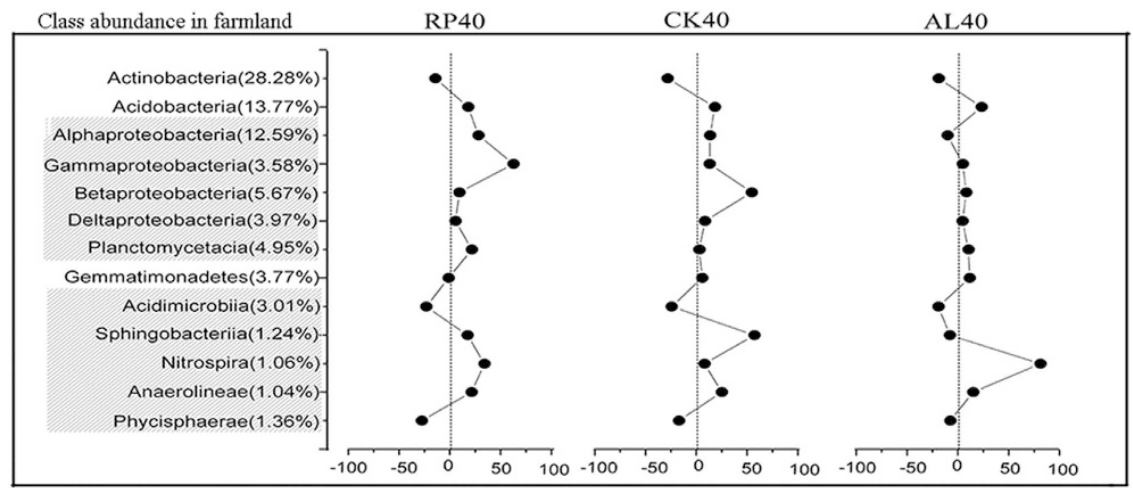

Percent change of the relative abundance in soil (\%)

Figure 4. Distribution of 16S rRNA sequences across bacterial class communities following afforestation.

Consequently, Mikkelson, et al. ${ }^{30}$ reported that hydrobiogeochemical processes are important for the growth of microbes and nutrient cycling. Afforestation of former land with RP and CK and the resultant terrestrial alterations are coupled to shifts in above- and below-ground microbial communities ${ }^{31-33}$. During the process of afforestation in our study area, increased soil $\mathrm{N}$ stocks were evidenced by increased litter inputs relative to farmland, and changes in soil properties, such as $\mathrm{pH}$ and SWC (Table 2 and Supplementary Table S1). It is possible that higher litter and root biomass in afforested ecosystems than farmland may influence the decomposition of organic matter ${ }^{12,27}$, further increase the $\mathrm{N}$ stocks and $\mathrm{cycles}^{6,34}$; meanwhile, the difference in soil water content and $\mathrm{pH}^{35,36}$, 


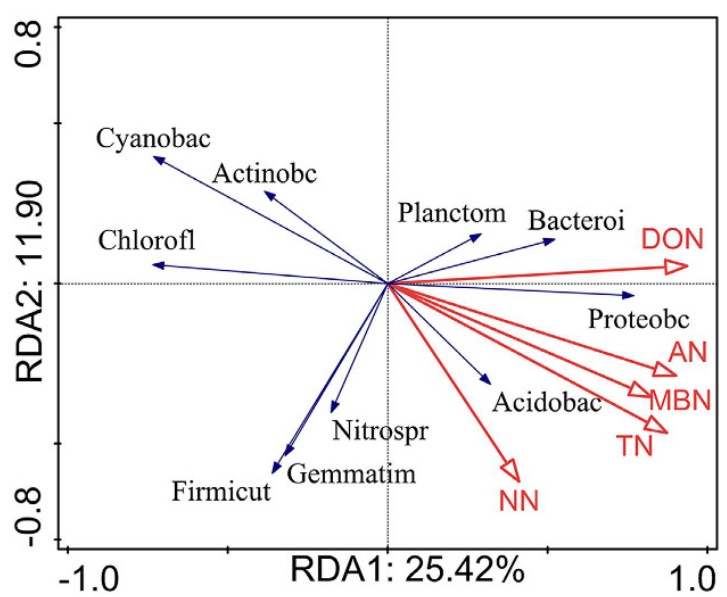

Figure 5. RDA analysis between soil $\mathbf{N}$ fractions and soil bacterial phyla following afforestation. The abbreviation were as follow: Proteobacteria (Proteobac), Actinobacteria (Actinoba), Acidobacteria (Acidobac), Chloroflexi (Chlorofl), Planctomycetes (Planctom), Gemmatimonadetes (Gemmatim), Bacteroidetes (Bacteroi), Cyanobacteria (Cyanobac), Nitrospirae (Nitrospi), Firmicutes (Firmicut), Armatimonadetes (Armatimo), Verrucomicrobia (Verrucom).

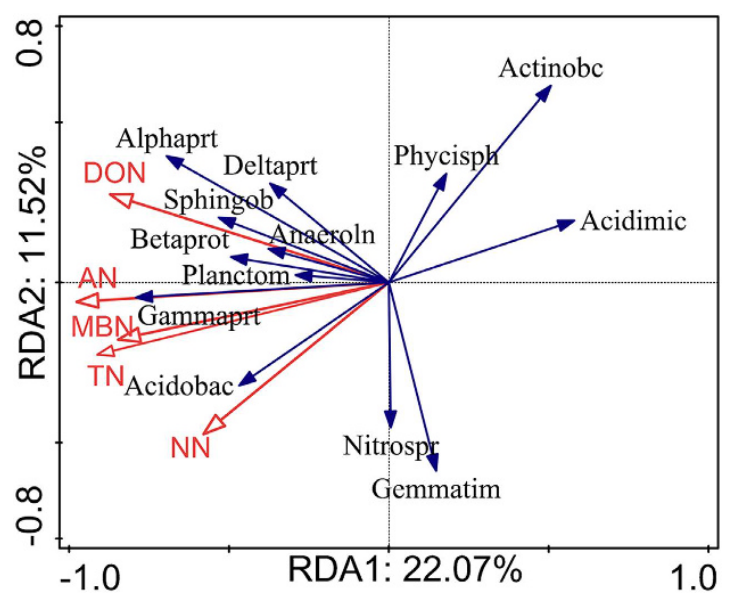

Figure 6. RDA analysis between soil $\mathrm{N}$ fractions and soil bacterial class following afforestation. The abbreviation were as follow: Actinobacteria (Actinoba), Acidobacteria (Acidobac) Alphaproteobacteria (Alphapro), Planctomycetacia (Planctom), Gammaproteobacteria (Gammapro), Betaproteobacteria (Betaprot), Deltaproteobacteria (Deltapro), Gemmatimonadetes (Gemmatim), Acidimicrobiia (Acidimic), Sphingobacteriia (Sphingob), Nitrospira (Nitrospi), Anaerolineae (Anaeroli), Phycisphaerae (Phycisph).

caused by land use, could also affect the mineralization rate of organic matter and $\mathrm{N}$ cycling, and as result alter $\mathrm{N}$ stocks ${ }^{9,37}$. Therefore, soil $\mathrm{N}$ stocks were higher in afforested soil (RP, CK, and AL), suggesting that cumulative changes in litter (litter and root biomass) and differences in soil parameters such as $\mathrm{pH}$ and water content can alter soil organic matter and possibly increase soil $\mathrm{N}$ stocks following afforestation.

Soil $\mathrm{N}$ fractions can be presented as $\mathrm{N}$-containing compounds (amino acids, amino sugars, and nucleic acids), which vary with litter deposition, roots, and plant compositions ${ }^{12,16,18}$. The present study showed that DON responded more significantly than the other $\mathrm{N}$ fractions following afforestation. Hence, it would suggest that DON, accounting for a large proportion of total soluble $\mathrm{N}$ stocks ${ }^{29}$, could easily be influenced by the above- and below-ground changes during afforestation. A subsequent study also evidenced that most forest soil N (96-98\%) contained in dead organic matter included complex insoluble polymers such as proteins, nucleic acids, and chitin, and these polymers are mainly broken down into $\mathrm{DON}^{29,38}$. Therefore, higher litter and root biomass in afforested systems may increase the availability of more insoluble polymers from altered dead organic matter inputs, resulting in higher DON contents.

Meanwhile, changes of the above-ground inputs and below-ground soil parameters also contributed to the differentiation of the soil microbial community ${ }^{28,39}$. Our study showed that soil bacterial communities differed significantly by afforestation, which were associated with decomposing needle litter and were coupled to changes in ecological parameters such as $\mathrm{pH}$ and SWC (Supplementary Table S1). Notably, soil bacterial abundance (16S rRNA gene copy) and alpha diversity (Shannon, $\mathrm{H}$ ) increased after afforestation. A possible explanation is that 


\begin{tabular}{|l|c|c|c|c|c|}
\hline \multicolumn{3}{|c|}{ Phylum level } & \multicolumn{3}{c|}{ Class level } \\
\hline $\begin{array}{l}\text { Number } \\
\text { variables }\end{array}$ & $\mathbf{R}$ & $\begin{array}{c}\text { Predictor } \\
\text { variables }\end{array}$ & $\begin{array}{c}\text { Number } \\
\text { variables }\end{array}$ & $\mathbf{R}$ & $\begin{array}{c}\text { Predictor } \\
\text { variables }\end{array}$ \\
\hline Global Test & $\mathrm{R}^{\mathrm{a}}=0.417$ & $\mathrm{P}^{\mathrm{c}}=3.3 \%$ & Global Test & $\mathrm{R}^{\mathrm{b}}=0.496$ & $\mathrm{P}^{\mathrm{d}}=0.9 \%$ \\
\hline 1 & $\mathbf{0 . 4 1 7}$ & $\mathbf{D O N}$ & $\mathbf{1}$ & $\mathbf{0 . 4 4 8}$ & DON \\
\hline 2 & $\mathbf{0 . 3 7 1}$ & DON, MBN & $\mathbf{2}$ & $\mathbf{0 . 4 9 6}$ & DON, MBN \\
\hline 2 & 0.337 & TN, DON & 2 & 0.377 & TN, DON \\
\hline 2 & 0.319 & AN, DON & 2 & 0.376 & AN, DON \\
\hline 2 & 0.196 & NN, DON & 3 & 0.470 & AN, DON, MBN \\
\hline 3 & 0.354 & AN, DON, MBN & 3 & 0.385 & TN, DON, MBN \\
\hline 3 & 0.300 & TN, DON, MBN & 3 & 0.339 & NN, DON, MBN \\
\hline 3 & 0.271 & TN, AN, DON & 3 & 0.304 & TN, AN, DON \\
\hline 3 & 0.225 & NN, DON, MBN & 4 & 0.321 & $\begin{array}{c}\text { TN, AN, DON, } \\
\text { MBN }\end{array}$ \\
\hline 4 & 0.229 & $\begin{array}{c}\text { TN, AN, DON, } \\
\text { MBN }\end{array}$ & 4 & 0.308 & $\begin{array}{c}\text { AN, NN, DON, } \\
\text { MBN }\end{array}$ \\
\hline 5 & 0.117 & $\begin{array}{c}\text { TN, AN, NN, } \\
\text { DON, MBN }\end{array}$ & 5 & 0.251 & $\begin{array}{c}\text { TN, AN, NN, } \\
\text { DON, MBN }\end{array}$ \\
\hline
\end{tabular}

Table 1. Results from "best" model selection procedure presented for each number of predictor variables of specific species at the phylum and class level (Relative abundance $>1 \%$ ). Number of permutations: 999 (Random sample). ${ }^{\mathrm{a} b}$ Means the Sample statistic (Average R); ${ }^{\mathrm{c} d}$ Means the significance level of sample statistic.

\begin{tabular}{|c|c|c|c|c|c|c|c|c|c|}
\hline Land use $^{\mathrm{a}}$ & Age (y) & Location & Elevation (m) & Slope aspect $\left({ }^{\circ}\right)$ & Litter- $N^{b}(g / k g)$ & FRB $^{c}\left(\mathrm{~kg} \mathrm{hm}^{-2}\right)$ & FRB-N $^{d}(\mathrm{~g} / \mathrm{kg})$ & $\mathrm{pH}$ & SWC $^{\mathrm{e}}(\%)$ \\
\hline $\begin{array}{l}\text { Robinia } \\
\text { pseudoacacia L }\end{array}$ & 40 & $36.87 \mathrm{~N}, 109.34 \mathrm{E}$ & 1320 & NbyE45 & $24.03( \pm 0.56)$ & $1350.75( \pm 20.80)$ & $17.70( \pm 0.28)$ & $8.31( \pm 0.01)$ & $20.20( \pm 1.16)$ \\
\hline $\begin{array}{l}\text { Caragana } \\
\text { Korshinskii Kom }\end{array}$ & 40 & $36.87 \mathrm{~N}, 109.35 \mathrm{E}$ & 1318 & NbyE10 & $25.49( \pm 1.07)$ & $1439.49( \pm 17.70)$ & $14.54( \pm 0.34)$ & $8.33( \pm 0.01)$ & $16.21( \pm 0.85)$ \\
\hline Abandoned land & 40 & $36.87 \mathrm{~N}, 109.35 \mathrm{E}$ & 1308 & NbyE30 & $8.72( \pm 1.37)$ & $587.86( \pm 17.29)$ & $7.32( \pm 0.14)$ & $8.45( \pm 0.01)$ & $14.62( \pm 0.35)$ \\
\hline Farmland & - & $36.87 \mathrm{~N}, 109.35 \mathrm{E}$ & 1273 & SbyW50 & No data & & & $8.48( \pm 0.01)$ & $10.10( \pm 0.94)$ \\
\hline
\end{tabular}

Table 2. Characteristics of four land use types. ${ }^{a}$ Means the conversion of farmland to different land use types, including Robinia pseudoacacia L (RP40a), Caragana korshinskii Kom (CK40a) and abandoned land (AL40a), Farmland, the original land use before vegetation restoration, served as the control in our study. b,c,d,e Represents the changes of litter nitrogen, fine root biomass, fine root nitrogen and soil water content after afforestation, which were determined in April 2014.

the nutrient resources, such as litter and root biomass, in the afforested ecosystems (RP, CK, and AL) were more abundant than those in the farmlands, and could provide more sufficient levels of nutrients for bacterial growth ${ }^{11}$. Compared with farmland, the amount of below-ground roots in RP and CK could liberate available nutrients associated with rhizosphere processes ${ }^{27}$ (i.e., forests have larger roots that farmland), thereby promoting the increase of community diversity ${ }^{11,40}$. This result was also evidenced by previous findings that plant nutrients imported to the soil in the form of litter and root exudates, and specifically selected for heterotrophic microbial communities ${ }^{40,41}$. Meanwhile, as soil bacterial diversity changed after afforestation (Figs 1 and 2), the relative taxonomic compositions of the soil bacteria differed significantly (Supplementary Tables S2 and S3 and Figure S1), suggesting that some specific clades were the primary contributors of soil microbial community structures. This phylum-level profile was similar to those in other soils and environments ${ }^{42,43}$. Regardless of afforestation, three dominant phyla, Proteobacteria, Acidobacteria, and Actinobacteria, were frequently discussed in previous studies $^{43-46}$ and reflected the soil conditions ${ }^{28,47}$. Many soil Proteobacteria have been described as fast growing copiotrophs that thrive in environments with high carbon availability, whereas Acidobacteria and Actinobacteria were oligotrophic groups that preferred nutrient-poor environments ${ }^{47,48}$. In the current study, soil bacterial compositions generally changed from Actinobacteria (Acidobacteria)-dominant in farmland to Proteobacteria-dominant in afforested soil (Figure S2), similarly to the increased soil nutrients after afforestation ${ }^{32}$, indicating that the soil bacterial community transitioned from oligotrophic to copiotrophic groups. Torsvik \& Øvrea ${ }^{49}$ also reported that these ratios were lower in oligotrophic soils and higher in copiotrophic soil with organic input. Hence, our study demonstrated that changes of soil dominant phyla (class) strongly modified soil bacterial diversity, and resultant alterations in soil may reflect the improvement of soil nutrient status after afforestation.

Soil microbial communities mediate ecological processes such as litter decomposition and mineralization ${ }^{16,41}$, causing considerable changes in soil $\mathrm{N}$ dynamics ${ }^{41}$ and ultimately resulting in an alteration to $\mathrm{N}_{\text {cycling }}{ }^{3}$. In the present study, soil bacterial diversity and dominant phyla were significantly correlated with soil $\mathrm{N}$ fractions, suggesting that increased soil $\mathrm{N}$ fractions after afforestation are responsible for the shift of soil microbial community structure. Interestingly, our study also revealed that DON was the most predictive factor structuring bacterial communities among $\mathrm{N}$ fractions, possibly since the accumulation of soil organic matter following afforestation may be broken down into DON through extracellular enzymes that are produced by soil microbes ${ }^{12}$. Farmland 
regenerated with plants could absorb more DON directly from the soil in the form of amino acids, through microbial mineralization ${ }^{16}$. Fierer, et al. ${ }^{50}$ also revealed that once $\mathrm{N}$ has access to DON pool, DON may be recycled and reused in microbial systems through free-living soil microbes and mineralization-immobilization of microbial biomass.

Additionally, soil microbes change the $\mathrm{N}$ cycling and availability by transforming $\mathrm{N}$ to more mobile forms ${ }^{12,16}$ and different $\mathrm{N}$ forms in soil are correlated with different bacterial processes that are involved in $\mathrm{N}$ cycling ${ }^{51}$. Thus, similarities in this study, increased soil $\mathrm{N}$ forms including DON, AN, and MBN, could suggest higher activity of nitrogen-fixing bacteria and ammonia oxidizing bacteria in forests ${ }^{29,51,52}$. The more significant orders under the four land use types belonged to Rhizobiales and Xanthomonadales, both of them belong to Proteobacteria phylum (Supplementary Table S4, Figure S2), which are associated with N fixation ${ }^{16}$. In particular, Rhizobiales, which are heterotrophic and nitrogen-fixing organisms ${ }^{16}$, were the most represented among the Alphaproteobacteria in afforested soil (RP, CK, 72\% each) and corresponded to increased N fractions (Supplementary Table S5, Fig. 1). In contrast, changes in Cyanobacteria were negatively correlated with soil $\mathrm{N}$ fractions (DON, AN, and MBN) in the present study, which was inconsistent with previous studies ${ }^{16,53}$ showing that nitrogen-fixing Cyanobacteria contribute to $\mathrm{N}$ accumulation in terrestrial ecosystems. Competition for nutrients with large Rhizobiales in afforested soil (RP, CK, AL) may explain the decreased abundance of Cyanobacteria we observed following afforestation. However, $\mathrm{NO}_{3}{ }^{-}-\mathrm{N}$ did not determine the soil bacterial compositions. This result is inconsistent with a previous study where $\mathrm{NO}_{3}{ }^{-}-\mathrm{N}$ played an important role in driving soil bacterial compositions during the secondary succession of abandoned land in the Loess Plateau ${ }^{28}$; however, both findings indicated that $\mathrm{NO}_{3}{ }^{-}-\mathrm{N}_{\text {could impact }}$ soil bacterial compositions in abandoned land. It is possible that forests compete with soil microbes for more $\mathrm{NO}_{3}{ }^{-}-\mathrm{N}^{12}$, resulting in a weak relationship between $\mathrm{NO}_{3}^{-}-\mathrm{N}$ and soil bacterial compositions. Both $\mathrm{NO}_{3}^{-}-\mathrm{N}^{-}$and the relative abundance of Nitrospira were higher in abandoned land than other land use types, also supporting the changes of $\mathrm{NO}_{3}^{-}-\mathrm{N}$ following afforestation. Consequently, our study demonstrated a relationship between soil $\mathrm{N}$ fractions and bacterial compositions, suggesting that soil $\mathrm{N}$ fractions changed with different soil bacterial compositions following afforestation. Although our study provides a scientific and reasonable explanation for the nitrogen fractions and the composition of soil bacteria following afforestation, there are also some uncertain factors that drove the changes in the underlying relative abundance of species, including temporal variability, with a snapshot and over time, perturbed environments, and more species colonized or that came out of dormancy. These factors are essential to discuss in a future study.

\section{Conclusions}

Our study documented that afforestation of former farmland, apart from influencing the above-ground plant compositions, resulted in below-ground that were characterized by changes of soil properties ( $\mathrm{pH}, \mathrm{SWC}$ ), $\mathrm{N}$ stocks, $\mathrm{N}$ fractions (TN, AN, NN, DON, MBN) and soil microbial community. Shifts in inputs with changes of plant compositions can increase the $\mathrm{N}$ stocks and fractions following afforestation. Similarity, soil bacterial abundance and diversity were also related with increased litter and root biomass. Changes of three dominant phyla such as Proteobacteria, Actinobacteria, and Acidobacteria could reflect the soil nutrients status after afforestation. Furthermore, $\mathrm{N}$ fractions were also correlated with soil bacterial phylum, especially for DON. Increases of other fractions also depended on changes of soil bacterial species. Thus, apart from the above inputs, the changes in the soil bacterial communities should be taken into account when assessing the effect of afforestation on the soil $\mathrm{N}$ stock and fractions on the Loess Hilly Region (LHR) of China and vice versa. In the future, more attention should be paid to plant-soil-microbe interactions from aboveground and belowground during $\mathrm{N}$ cycling.

\section{Methods \\ Study area. This study was conducted in the Wuliwan catchment, located in the middle area of the Loess Plateau $\left(36^{\circ} 51^{\prime} 41.23^{\prime \prime}-36^{\circ} 52^{\prime} 50.87^{\prime \prime} \mathrm{N}, 109^{\circ} 19^{\prime} 49.20^{\prime \prime}-109^{\circ} 21^{\prime} 46.46^{\prime \prime} \mathrm{E}\right)$ (Fig. 7). The study site is a temperate sem- iarid area with average annual temperature of $8.8^{\circ} \mathrm{C}$ and average annual precipitation of $510 \mathrm{~m}$ (mainly from July to September). Moreover, the accumulated temperatures above $0^{\circ} \mathrm{C}$ and $10^{\circ} \mathrm{C}$ were $3733^{\circ} \mathrm{C}$ and $3283^{\circ} \mathrm{C}$, respec- tively. The frost-free period is 157 days, and the sunny time is $2415 \mathrm{~h}$ per year. The soil is mainly highly erodible Huangmian soil (Calcaric Cambisols, FAO). \\ The study catchment, the Wuliwan catchment, has been an experimental site of the Institute of Soil and Water Conservation, Chinese Academy of Science (CAS) since 1973. Widespread vegetation restoration has been imple- mented to remedy the soil degradation problem during the past decade. As shown in Fig. 7, samples were col- lected from farmlands mainly replanted with Robinia pseudoacacia L. (RP) or Caragana Korshinskii Kom (CK) and from abandoned land. Details of four land use types are provided in Table 2 and Supplementary Table S5, which were determined in April 2014, including litter-N (mean $19.41 \mathrm{~g} / \mathrm{kg}$ ), FRB (mean $1126.03 \mathrm{~kg} \cdot \mathrm{hm}^{-2}$ ), fine root $\mathrm{N}$ (mean $13.19 \mathrm{~g} / \mathrm{kg}$ ), pH (mean 8.39) and SWC (mean 15.28\%); all the data in our study showed an increas- ing trend except $\mathrm{pH}$.}

Sample collection. Sampling was carried out in April 2014. Based on the vegetation restoration project, three 40-year-old land types, Robinia pseudoacacia L. (RP40), Caragana Korshinskii Kom (CK40), abandoned land (AL40), and one farmland (FL) planted with millet (Setaria italica) were selected. Moreover, both Robinia pseudoacacia L. (RP) and Caragana korshinskii Kom. (CK) have been widely restored on the Loess Plateau. The abandoned land (AL40) that was afforested from farmland was not tilled for 40 years. For each land use type, we sampled three replicates for a total of 12 forested sites (three $25 \mathrm{~m} \times 50 \mathrm{~m}$ ), and in each site $(25 \mathrm{~m} \times 50 \mathrm{~m}$ ), we designed two plots with sizes of $25 \mathrm{~m} \times 25 \mathrm{~m}$, which were also located on the same physiographic units; prior to afforestation, all the plots were essentially farmlands. 


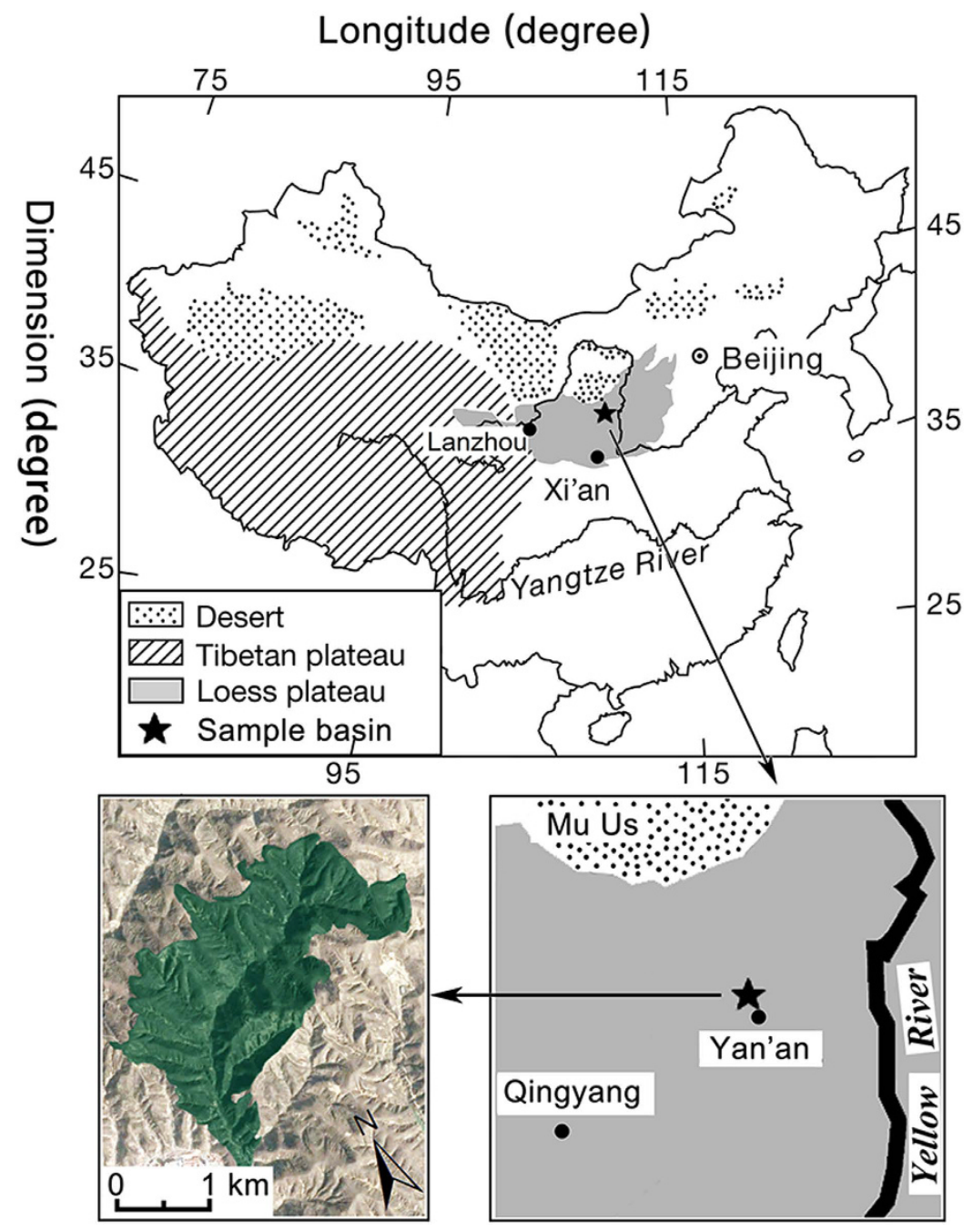

Figure 7. Location of the Loess Plateau and the study basin, Maps generated using ArcGIS (10.0) (http://www.esri.com/software/arcgis).

A total of 24 samples ( 4 land use types $\times 3$ sites $\times 2$ plots) were collected from the top $0-10 \mathrm{~cm}$ using a soil auger (diameter $5 \mathrm{~cm}$ ) from the four land use types. Briefly, after removing the litter layer, we collected 10 samples with an " $\mathrm{S}$ " shape and incorporated spatial heterogeneity at the plot scale, for a total of six replicate soil samples per land use type. The samples were immediately sieved through $2-\mathrm{mm}$ mesh to eliminate large rocks and roots. A part of the soil samples to be used for DNA extraction were transported from field to laboratory in ice bags and then stored in the laboratory at $-80^{\circ} \mathrm{C}$. A second portion to be used to determine the total nitrogen were air-dried and stored at room temperature; another part of the soil samples to be used to determine the other $\mathrm{N}$ fractions were stored at $4{ }^{\circ} \mathrm{C}$. Additionally, three soil profiles were dug randomly in each plot and were sampled in each sampling interval to determine the soil bulk density.

Soil chemical properties. The total nitrogen $(\mathrm{TN})\left(\mathrm{g} \cdot \mathrm{kg}^{-1}\right)$ was determined using the Kjeldahl method, and the contents of ammonium nitrogen $(\mathrm{AN})\left(\mathrm{mg} \cdot \mathrm{kg}^{-1}\right)$ and nitrate nitrogen $(\mathrm{NN})\left(\mathrm{mg} \cdot \mathrm{kg}^{-1}\right)$ were determined using $\mathrm{KCl}$ digestion, whereas the dissolved organic nitrogen (DON) was determined using potassium peroxy disulfate oxidation before the treated liquids were assessed by an Automated Chemistry Analyzer ${ }^{54}$, and the soil microbial nitrogen $(\mathrm{MBN})\left(\mathrm{mg} \cdot \mathrm{kg}^{-1}\right)$ was measured using the chloroform fumigation extraction method ${ }^{55}$.

Calculation of the $\mathbf{N}$ stocks. The $\mathrm{N}$ stocks represented the soil total $\mathrm{N}$ (STN) storage at each sampling depth. The $\mathrm{N}$ stocks of different sampling depths were calculated as follows:

$$
N_{\text {stocks }}=C_{S T N} \times \rho \times H \times(1-\delta / 100) \times 10^{-1}
$$

where $\mathrm{N}$ stocks is the density $\left(\mathrm{Mg} \cdot \mathrm{ha}^{-1}\right)$ of TN, $\mathrm{C}_{\text {STN }}$ is the content $\left(\mathrm{g} \cdot \mathrm{kg}^{-1}\right)$ of STN, $\rho$ is the bulk density $\left(\mathrm{g} \cdot \mathrm{cm}^{-3}\right)$, $\mathrm{H}$ is the soil horizon thickness $(\mathrm{cm})$, and $\delta$ is the fraction (\%) of gravels $>2 \mathrm{~mm}$ in size in the soil. Because the soil gravel size of loess in China is mostly below $2 \mathrm{~mm}$, this fraction was assumed to be $0^{56}$. 
Soil DNA extraction. DNA was extracted from $0.5 \mathrm{~g}$ of each fresh soil sample and homogenized from 10 points with E.Z.N.A soil DNA (OMEGA, USA). The concentration and quality of the DNA were measured using a spectrophotometer (NanoDrop2000, ThermoScientific, Wilmington, DE, USA). The extracted soil DNA was stored at $-80^{\circ} \mathrm{C}$ for PCR amplification and analysis.

Quantitative PCR. Bacterial 16S rRNA copy numbers were estimated by primer set 515F (5'-GTGC CAGCMGCCGCGG-3') and 907R (5'-CCGTCAATTCMTTTRAGTTT-3' ${ }^{57}$. The abundance of bacterial small-subunit rRNA gene copies were quantified against standard curves generated from a 10 -fold serial dilution of cloned full-length copies of either 16S rRNA gene. The reactions were carried out using an ABI Prism 7900 Sequence Detection System (Applied Biosystems, USA). Quantification was based on the fluorescence intensity of the SYBR Green dye during amplification. The $20 \mu \mathrm{l}$ qPCR reactions contained $10 \mu \mathrm{l}$ EvaGreen $2 \mathrm{X}$ qPCR MasterMix (Applied Biological Materials Inc., Richmond, Canada), a final concentration of each primer of $0.5 \mu \mathrm{M}$, and an environmental and standard DNA template at $1 \mu \mathrm{l}$ per reaction to bacteria. The plates were run with the following cycle: $40 \mathrm{cycles}$ of $95^{\circ} \mathrm{C}$ for $15 \mathrm{~s}, 53^{\circ} \mathrm{C}$ for $30 \mathrm{~s}$ and $72{ }^{\circ} \mathrm{C}$ for $60 \mathrm{~s}$. All of the qPCR reactions were run in triplicate with each DNA template. The amplification efficiency of the qPCR was $86-97 \%\left(\mathrm{R}^{2}>0.992\right)$.

PCR amplification and sequencing of 16S rRNA genes. PCR amplification of the bacterial 16S rRNA targeting the V4 region ${ }^{58}$ was conducted. The primers were $515 \mathrm{~F}$ and $907 \mathrm{R}^{57}$. The PCR reaction system contained $0.4 \mu \mathrm{l}$ of the two primers, $0.4 \mu \mathrm{l}$ of FastPfu polymerase, and $10 \mathrm{ng} 1.25 \mu \mathrm{l}$ of template DNA. After preparation, the samples were denatured at $95^{\circ} \mathrm{C}$ for $3 \mathrm{~min}$, then amplified using 27 cycles of $95^{\circ} \mathrm{C}$ for 30 seconds, $55^{\circ} \mathrm{C}$ for 30 seconds, and $72^{\circ} \mathrm{C}$ for 45 seconds, followed by an extension at $72^{\circ} \mathrm{C}$ for $10 \mathrm{~min}$. Each sample was amplified three times. PCR products were extracted from $2 \%$ agarose gels and purified using the AxyPrep DNA Gel Extraction Kit (Axygen Biosciences, Union City, CA, US). Finally, according to the manufacturer's instructions, an equal amount of PCR product from each sample was combined in a single tube according to the manufacturer's instructions and sent to Illumina's MiSeq platform at the Major Biological Institute in Shanghai, China.

Processing of 16S rRNA gene data. The reads were demultiplexed, quality-filtered, and processed using QIIME and based on three criteria. First, the 300-bp reads were truncated at any site with an average quality score $<20$ over a 50 -bp sliding window. The truncated reads that were shorter than $50 \mathrm{bp}$ were then discarded. Second, exact barcode matching, two-nucleotide mismatches in primer matching, and reads containing ambiguous characters were removed. Third, only sequences that overlapped longer than $10 \mathrm{bp}$ were assembled according to their overlap sequence. Reads that could not be assembled were discarded. Operational Taxonomic Units (OTUs) were clustered with a 97\% similarity cutoff using UPARSE (version $7.1 \mathrm{http}: / /$ drive 5.com/uparse/), and chimeric sequences were identified and removed using UCHIME. The taxonomy of each 16S rRNA gene sequence was analyzed by RDP Classifier (http://rdp.cme.msu.edu/) against the Silva (SSU115) 16S rRNA database using a confidence threshold of $70 \%$. Finally, the complete dataset was sent to the Sequence Read Archive (SRA) database of the National Center for Biotechnology Information (NCBI) under the accession number of SRP056716.

Bioinformatics analysis. The calculated indices related to alpha diversity, including the Simpson index and Shannon index, which were determined by mothur (version v.1.30.1), were used to show the community diversity. Unweighted-Unifracted PcoA was performed to assess the cluster of soil bacterial communities according to land use types ${ }^{44}$. MEGAN was used to determine the phylogenetic analysis of the bacteria after conversion ${ }^{59}$. The similarities were determined to test whether there were significant differences in the microbial communities among the four land use types using "Adonis," a vegan package in the R environment.

Pearson correlations among litter, litter-N, fine root biomass, fine root- $\mathrm{N}$, soil $\mathrm{N}$ fractions, bacterial abundance and alpha diversity (Shannon index, H) were determined using the SPSS 22.0 software package. The linear regression analysis between the PcoA 1 and the SWC and pH were calculated using the SPSS 22.0 software package. The changes in the soil $\mathrm{N}$ stocks and fractions and the soil bacterial abundance and diversity among the land use types were tested with One-Way ANOVA using the R v.3.1.3 program. All p-values were considered significant if at or below the 0.05 threshold. Additionally, we used the "best" model building procedure in PRIMER v.7 to identify all possible combinations of factors that contributed to the highest proportion of soil bacterial phylum and other species; factor addition was evaluated stepwise and was based on sufficient improvement in the model's $\mathrm{R}^{60}$. Redundancy analysis (RDA) was used to identify the relationship between the soil specific bacterial species and $\mathrm{N}$ fractions. This analysis was performed using the CANOCO 4.5 software package ${ }^{61}$.

\section{References}

1. Canadell, J. G. \& Raupach, M. R. Managing forests for climate change mitigation. Science. 320, 1456-1457 (2008).

2. Miles, L. \& Kapos, V. Reducing greenhouse gas emissions from deforestation and forest degradation: global land-use implications. Science. 320, 1454-1455 (2008).

3. Bru, D. et al. Determinants of the distribution of nitrogen-cycling microbial communities at the landscape scale. ISME J. 5, 532-542 (2011).

4. Bardgett, R. D. et al. Parasitic plants indirectly regulate below-ground properties in grassland ecosystems. Nature. 439, 969-972 (2006).

5. Li, M., Zhou, X., Zhang, Q. \& Cheng, X. Consequences of afforestation for soil nitrogen dynamics in central China. Agr Ecosyst Environ. 183, 40-46 (2014).

6. Li, D., Niu, S. \& Luo, Y. Global patterns of the dynamics of soil carbon and nitrogen stocks following afforestation: a meta-analysis. New Phytol. 195, 172-181 (2012).

7. Leavit, S. W. Biogeochemistry, An Analysis of Global Change. Eos, Transactions American Geophysical Union. 79, 20-20 (1998). 
8. Deng, Q., Cheng, X., Yang, Y., Zhang, Q. \& Luo, Y. Carbon-nitrogen interactions during afforestation in central China. Soil Biol. Biochem. 69, 119-122 (2014).

9. Liu, Z.-P., Shao, M.-A. \& Wang, Y.-Q. Spatial patterns of soil total nitrogen and soil total phosphorus across the entire Loess Plateau region of China. Geoderma. 197-198, 67-78 (2013).

10. Xue, Z., Cheng, M. \& An, S. Soil nitrogen distributions for different land uses and landscape positions in a small watershed on Loess Plateau, China. Ecol Eng. 60, 204-213 (2013).

11. Philippot, L., Raaijmakers, J. M., Lemanceau, P. \& van der Putten, W. H. Going back to the roots: the microbial ecology of the rhizosphere. Nat. Rev. Microbiol. 11, 789-799 (2013).

12. Schimel, J. P. \& Bennett, J. Nitrogen mineralization: challenges of a changing paradigm. Ecology. 85, 591-602 (2004).

13. Aerts, R., Van Bodegom, P. \& Cornelissen, J. Litter stoichiometric traits of plant species of high-latitude ecosystems show high responsiveness to global change without causing strong variation in litter decomposition. New Phytol. 196, 181-188 (2012).

14. Wieder, W. R. et al. Experimental removal and addition of leaf litter inputs reduces nitrate production and loss in a lowland tropical forest. Biogeochemistry. 113, 629-642 (2013).

15. Blaško, R. et al. Shifts in soil microbial community structure, nitrogen cycling and the concomitant declining $\mathrm{N}$ availability in ageing primary boreal forest ecosystems. Soil Biol. Biochem. 91, 200-211 (2015).

16. Van Der Heijden, M. G., Bardgett, R. D. \& Van Straalen, N. M. The unseen majority: soil microbes as drivers of plant diversity and productivity in terrestrial ecosystems. Ecol Lett. 11, 296-310 (2008).

17. Iqbal, J. et al. Microbial biomass, and dissolved organic carbon and nitrogen strongly affect soil respiration in different land uses: a case study at Three Gorges Reservoir Area, South China. Agr Ecosyst Environ. 137, 294-307 (2010).

18. Wei, C. et al. Nitrogen deposition weakens plant-microbe interactions in grassland ecosystems. Global change biol. 19, 3688-3697 (2013).

19. Bai, Z. \& Dent, D. Recent land degradation and improvement in China. AMBIO: A Journal of the Human Environment. 38, 150-156 (2009).

20. Zhang, C., Liu, G., Xue, S. \& Wang, G. Changes in rhizospheric microbial community structure and function during the natural recovery of abandoned cropland on the Loess Plateau, China. Ecol Eng. 75, 161-171 (2015).

21. Zhang, Y.-w., Deng, L., Yan, W.-m. \& Shangguan, Z.-p. Interaction of soil water storage dynamics and long-term natural vegetation succession on the Loess Plateau, China. Catena. 137, 52-60 (2016).

22. Zhao, F. et al. Land use change influences soil C, N, and P stoichiometry under 'Grain-to-Green Program' in China. Sci. Rep. 5, 10195, doi: 10.1038/srep10195 (2015).

23. Liu, J., Li, S., Ouyang, Z., Tam, C. \& Chen, X. Ecological and socioeconomic effects of China's policies for ecosystem services. Proc. Natl. Acad. Sci. 105, 9477-9482 (2008).

24. Cao, S., Chen, L. \& Yu, X. Impact of China’s Grain for Green Project on the landscape of vulnerable arid and semi-arid agricultural regions: a case study in northern Shaanxi Province. J Appl Ecol. 46, 536-543 (2009).

25. Deng, L., Shangguan, Z.-p. \& Sweeney, S. "Grain for Green" driven land use change and carbon sequestration on the Loess Plateau, China. Sci. Rep. 4, 7039, doi: 10.1038/srep07039 (2014).

26. Zhang, C., Xue, S., Liu, G.-B. \& Song, Z.-L. A comparison of soil qualities of different revegetation types in the Loess Plateau, China. Plant Soil. 347, 163-178 (2011).

27. Xin, L., Rui-ping, M., Shao-shan, A., Quan-chao, Z. \& Ya-yun, L. Characteristics of soil organic carbon and enzyme activities in soil aggregates under different vegetation zones on the Loess Plateau. Chinese Journal of Applied ecology. 26, 2282-2290 (2015).

28. Zhang, C., Liu, G., Xue, S. \& Wang, G. Soil bacterial community dynamics reflect changes in plant community and soil properties during the secondary succession of abandoned farmland in the Loess Plateau. Soil Biol. Biochem. 97, 40-49 (2016).

29. Jones, D. L., Shannon, D., V. Murphy, D. \& Farrar, J. Role of dissolved organic nitrogen (DON) in soil N cycling in grassland soils. Soil Biol. Biochem. 36, 749-756 (2004).

30. Mikkelson, K. M. et al. Bark beetle infestation impacts on nutrient cycling, water quality and interdependent hydrological effects. Biogeochemistry. 115, 1-21 (2013).

31. Zhang, C., Liu, G., Xue, S. \& Song, Z. Rhizosphere soil microbial activity under different vegetation types on the Loess Plateau, China. Geoderma. 161, 115-125 (2011).

32. Zhao, F. et al. Soil stoichiometry and carbon storage in long-term afforestation soil affected by understory vegetation diversity. Ecol Eng. 74, 415-422 (2015).

33. Qiu, L., Zhang, X., Cheng, J. \& Yin, X. Effects of black locust (Robinia pseudoacacia) on soil properties in the loessial gully region of the Loess Plateau, China. Plant Soil. 332, 207-217 (2010).

34. Deng, L., Liu, G. b. \& Shangguan, Z. p. Land-use conversion and changing soil carbon stocks in China’s 'Grain-for-Green'Program: a synthesis. Global change biol. 20, 3544-3556 (2014).

35. Wang, S., Fu, B., Gao, G., Liu, Y. \& Zhou, J. Responses of soil moisture in different land cover types to rainfall events in a revegetation catchment area of the Loess Plateau, China. Catena. 101, 122-128 (2013).

36. Liu, Z. P., Shao, M. A. \& Wang, Y. Q. Large-scale spatial interpolation of soil pH across the Loess Plateau, China. Environ Earth Sci. 69,2731-2741 (2013).

37. Guntiñas, M. E., Leirós, M. C., Trasar-Cepeda, C. \& Gil-Sotres, F. Effects of moisture and temperature on net soil nitrogen mineralization: A laboratory study. Eur J Soil Biol. 48, 73-80 (2012).

38. Smolander, A. \& Kitunen, V. Comparison of tree species effects on microbial $\mathrm{C}$ and $\mathrm{N}$ transformations and dissolved organic matter properties in the organic layer of boreal forests. Appl. Soil Ecol. 49, 224-233 (2011).

39. Šnajdr, J. et al. Dominant trees affect microbial community composition and activity in post-mining afforested soils. Soil Biol. Biochem. 56, 105-115 (2013).

40. Singh, B. K., Millard, P., Whiteley, A. S. \& Murrell, J. C. Unravelling rhizosphere-microbial interactions: opportunities and limitations. Trends Microbiol. 12, 386-393 (2004).

41. Deng, Q. et al. Soil microbial community and its interaction with soil carbon and nitrogen dynamics following afforestation in central China. Sci Total Environ. 541, 230-237 (2016).

42. Lee-Cruz, L., Edwards, D. P., Tripathi, B. M. \& Adams, J. M. Impact of logging and forest conversion to oil palm plantations on soil bacterial communities in Borneo. Appl Environ Microbiol. 79, 7290-7297 (2013).

43. Xiang, X. et al. Rapid recovery of soil bacterial communities after wildfire in a Chinese boreal forest. Sci. Rep. 4, 3829, doi: 10.1038/ srep03829 (2014).

44. Lauber, C. L., Ramirez, K. S., Aanderud, Z., Lennon, J. \& Fierer, N. Temporal variability in soil microbial communities across landuse types. ISME J. 7, 1641-1650 (2013).

45. Liu, J. et al. High throughput sequencing analysis of biogeographical distribution of bacterial communities in the black soils of northeast China. Soil Biol. Biochem. 70, 113-122 (2014).

46. Rodrigues, J. L. et al. Conversion of the Amazon rainforest to agriculture results in biotic homogenization of soil bacterial communities. Proc. Natl. Acad. Sci. 110, 988-993 (2013).

47. Fierer, N., Bradford, M. A. \& Jackson, R. B. Toward an ecological classification of soil bacteria. Ecology. 88, 1354-1364 (2007).

48. Hill, P. et al. Land Use Intensity Controls Actinobacterial Community Structure. Microbial Ecol. 61, 286-302 (2010).

49. Torsvik, V. \& Øvreås, L. Microbial diversity and function in soil: from genes to ecosystems. Curr Opon Microbiol. 5, 240-245 (2002). 
50. Fierer, N., Schimel, J. P., Cates, R. G. \& Zou, J. Influence of balsam poplar tannin fractions on carbon and nitrogen dynamics in Alaskan taiga floodplain soils. Soil Biol. Biochem. 33, 1827-1839 (2001).

51. Isobe, K. \& Ohte, N. Ecological perspectives on microbes involved in N-cycling. Microbes Environ. 29, 4-16 (2014).

52. Isobe, K. et al. Microbial regulation of nitrogen dynamics along the hillslope of a natural forest. Front. Environ. Sci. 2, 63 (2015)

53. DeLuca, T. H., Zackrisson, O., Nilsson, M.-C. \& Sellstedt, A. Quantifying nitrogen-fixation in feather moss carpets of boreal forests. Nature. 419, 917-920 (2002).

54. Bao, S. D. Soil and agricultural chemistry analysis. (China Agriculture Press, Beijing, 2000).

55. Brookes, P. C., Landman, A., Pruden, G. \& Jenkinson, D. Chloroform fumigation and the release of soil nitrogen: a rapid direct extraction method to measure microbial biomass nitrogen in soil. Soil Biol. Biochem. 17, 837-842 (1985).

56. Wan, X. et al. Effects of broadleaf plantation and Chinese fir (Cunninghamia lanceolata) plantation on soil carbon and nitrogen pools. J Appl Ecol. 24, 345-350 (2013).

57. Biddle, J. F., Fitz-Gibbon, S., Schuster, S. C., Brenchley, J. E. \& House, C. H. Metagenomic signatures of the Peru Margin subseafloor biosphere show a genetically distinct environment. Proc. Natl. Acad. Sci. 105, 10583-10588 (2008).

58. Taş, N. et al. Impact of fire on active layer and permafrost microbial communities and metagenomes in an upland Alaskan boreal forest. ISME J. 8, 1904-1919 (2014).

59. Huson, D. H., Auch, A. F., Qi, J. \& Schuster, S. C. MEGAN analysis of metagenomic data. Genome Res. 17, 377-386 (2007).

60. Clarke, K. R., Gorley, R. N., Somerfield, P. J. \& R. M., W. Change in marine communities: An approach to statistical analysis and interpretation. 3nd edn, 1-300 (PRIMER-E: Plymouth, UK, 2014).

61. Braak, C. t. \& Smilauer, P. CANOCO Reference Manual and CanoDraw for Windows, Users Guide. (Microcomputer Power, Ithaca, NY ASA, 2002)

\section{Acknowledgements}

The authors especially thank Jianping Wu, Luhong Zhao (Northwest A\&F University) for their help with the fieldwork and this work was supported by the National Natural Science Foundation of China (41301601) and Special Fund for forest-scientific Research in the Public Interest (201304312).

\section{Author Contributions}

X.H.H. and G.H.Y. conceived and designed the experiments. C.J.R., P.S.S. and F.Z.Z. carried out the experiments. D.K. plot the figures. C.J.R. wrote the paper. Professor G.X.R. and Y.Z.F. worked on text and language correction All authors reviewed the manuscript.

\section{Additional Information}

Supplementary information accompanies this paper at http://www.nature.com/srep

Competing financial interests: The authors declare no competing financial interests.

How to cite this article: Ren, C. et al. Responsiveness of soil nitrogen fractions and bacterial communities to afforestation in the Loess Hilly Region (LHR) of China. Sci. Rep. 6, 28469; doi: 10.1038/srep28469 (2016).

(c) (i) This work is licensed under a Creative Commons Attribution 4.0 International License. The images or other third party material in this article are included in the article's Creative Commons license, unless indicated otherwise in the credit line; if the material is not included under the Creative Commons license, users will need to obtain permission from the license holder to reproduce the material. To view a copy of this license, visit http://creativecommons.org/licenses/by/4.0/ 